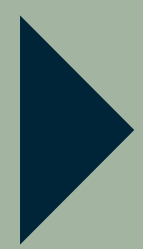




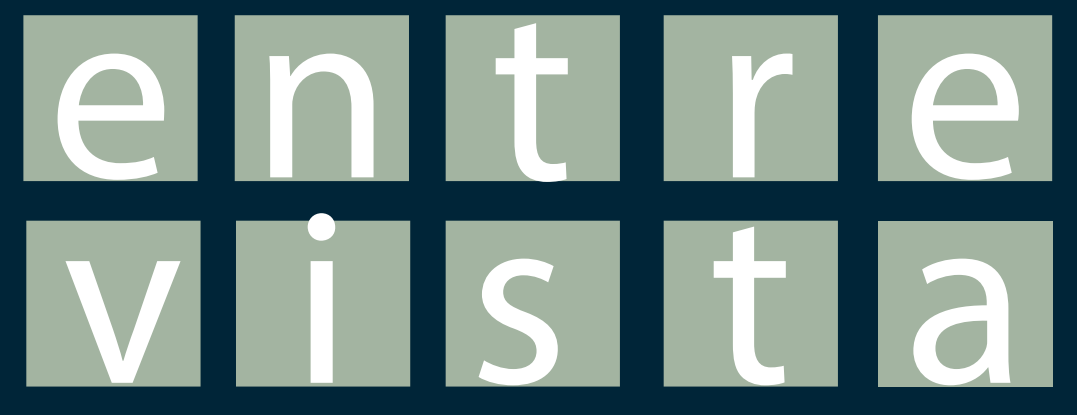




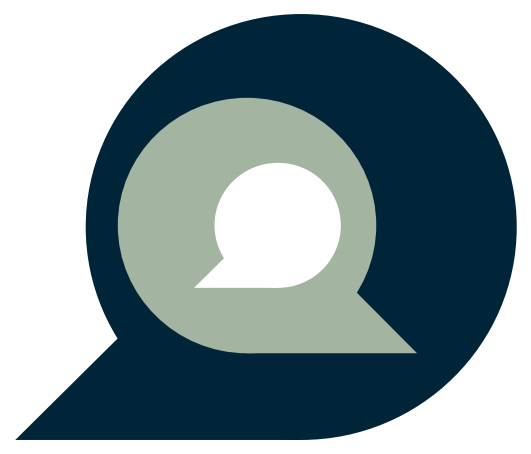




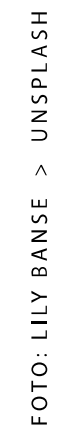

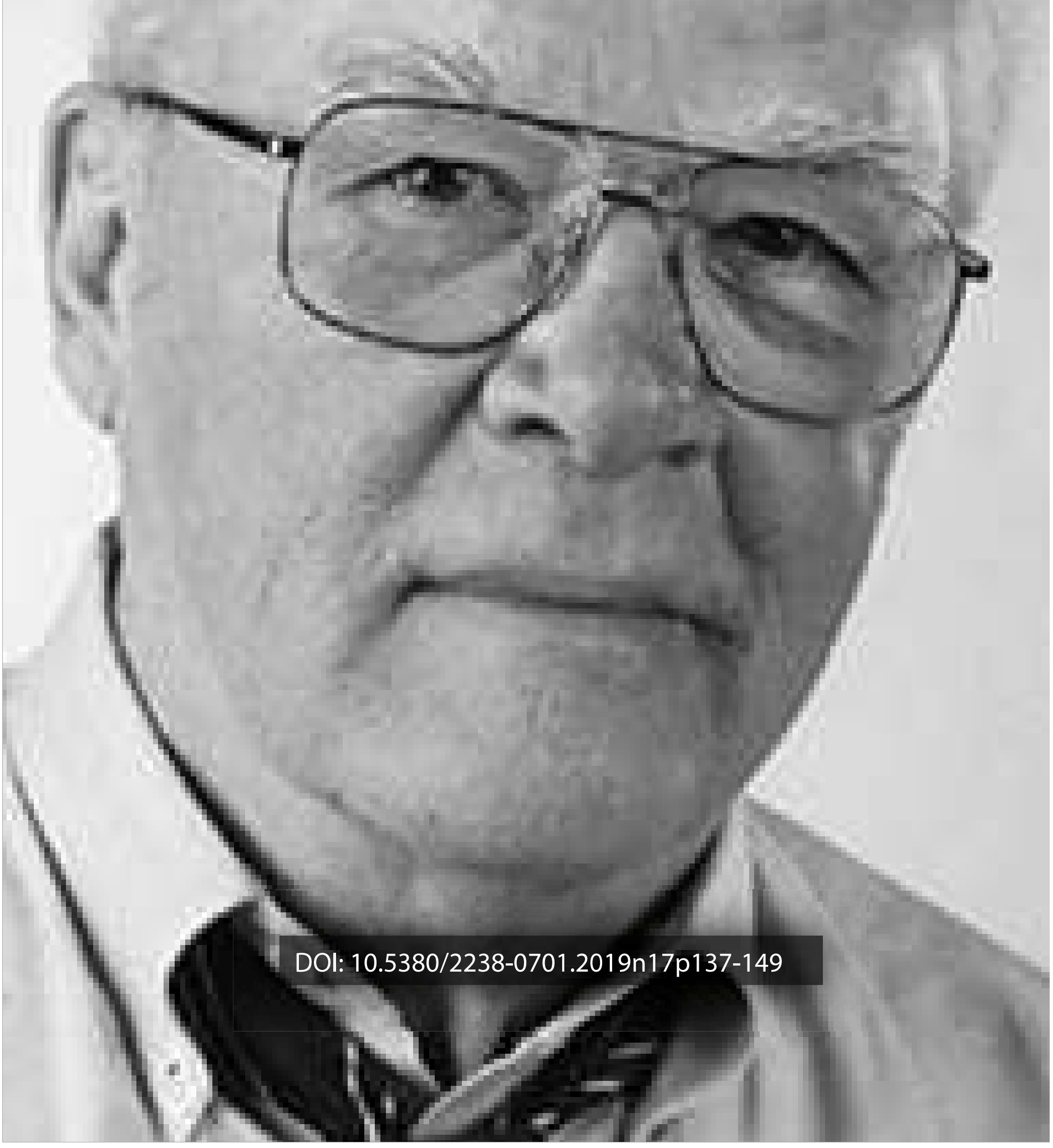


The Civic Journalism / Public Journalism examined by one of its creators.

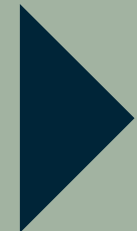




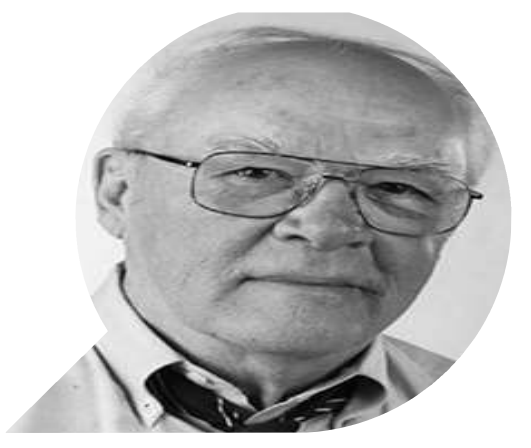

\section{The Civic Journalism / Public Journalism examined by one of its creators}

\section{MARCIO FERNANDES ${ }^{1}$}

Davis Merritt is a legend in International Journalism. Legend in the best sense that the word can have. Author of four books (the most recent in 2015, called On life, liberty and the pursuit of perfect), has been at the top of American Journalism for more than four decades, working especially for the Knight Newspapers chain. He served as a professor at the University of Kansas and at Wichita State University. Between 1975 and 1997, he served as head of the Wichita Eagle, a diary in which he would make history, laying the foundations of what is now known as Civic Journalism (CJ), a proposal founded on the idea that, rather than simply denouncing life's problems in society, the journalist must think about solutions and, especially, stimulate citizen participation in collective life.

In the following interview, Merritt shares invaluable information about this movement that emerged in the late 1980s, gained in the 1990s, and began to languish in 2000. In its maximum moment, the Civic Journalism was news and produced news in the US, Colombia , Bolivia, Argentina, Brazil, Portugal, Spain and many other countries. Merritt recalls the inaugural times (including highlighting the

1 Marcio Fernandes is an academic researcher and leader in educational projects involving Latin America and Europe. Journalist with 23 years of experience in Brazil and abroad, he has $\mathrm{PhD}$ in Communication and Culture (UFRJ/Brazil and UL/Portugal) and author of several papers about Civic Journalism, published in many countries. Permanent teacher of the Social Communication Department of the Universidade Estadual do Centro-Oeste (in Portuguese, Unicentro/Brazil). E-mail: marciofernandes@unicentro.br 
role of Jay Rosen, considered the other creator of CJ), clarifies the Civic Journalism / Public Journalism (more than 30 years after his initial concerns about Journalism's, so he prefers, as one perceives in all his answers) and thinks about the present time.

On this issue Civic Journalism / Public Journalism (PJ), it is possible to emphasize what follows: all the questions made to Merritt make mention to the Civic Journalism, since this is the denomination better known in Brazil and in other places. As a matter of respect for the interviewee's opinion, we kept $P J$ in his responses. This duality is part of the richness of this talk about one of the most innovative ways of thinking and doing Journalism in the last 50 years. Read more:

Keywords: Civic Journalism; Public Journalism; Democracy;

DM: Before I begin responding to your questions, I'd like to clarify the confusion over the name of the idea. I call it Public Journalism because that is the name that Jay Rosen and I settled upon while we were thinking together about the concept, starting in 1993 . Because the concept was new, we recognized that it needed a name, but feared that giving it one would put it in a box. We were not trying to build a "thing" that could fit into a box; we were trying to start a discussion within the profession about how the relationship between Journalism and Democracy could be more effective for both.

Eventually, we chose "public" for two primary reasons: 1) We were talking about the dynamics of public life-how democracy is expressed and experienced, and 2) we would be public and open about our intentions. After Jay and I published a first iteration of the ideas ("Public Journalism Theory and Practice) in 1994 and the idea began to rouse some discussion within the profession, Ed Fouhy, a former network news producer, visited Wichita for two days to talk about the idea. Later that year, with money provided by the Pew Charitable Trust, he used our ideas to open the Center for Civic Journalism. Why he felt the need to change the name was never explained. Since the Center was backed by millions of Pew dollars, it was able to generate attention that a newspaper editor and a Journalism professor could not, so people began to adapt the news term 'Civic Journalism'. 
In 1995, I published the first book on the subject (Public Journalism and Public Life: Why Telling the News is Not Enough). Unfortunately, confusion over the name made it much more difficult to persuade tradition-bound U.S. journalists to understand and adopt the practices we were exploring. To be fair, the Center for Civic Journalism without question did a great deal to spread some of the ideas within the profession, using millions to help finance reporting projects around the country.

MF - About 30 years ago, you presented the idea of the Civic Journalism (CJ), from your experience as editor-in-chief of the Wichita Eagle newspaper. Is it already possible to take stock of what we might call the 'legacy of Civic Journalism'?

DM: It is extremely difficult to weigh and measure the "legacy" of Public Journalism from the vantage point of 2019. Without doubt, it had some impact on how Journalism was practiced in the 1990s and early 2000s, and certainly the discussion that Jay and I wanted to stimulate did take place: there are more than fifty books and hundreds of academic papers on the subject in several languages. But because Public Journalism is as much a state of mind as it is a particular way of doing Journalism, it's impossible to gauge its impact on today's journalists. I occasionally see examples today that I would consider to be in the spirit and mode of Public Journalism, but it's impossible to make a concrete connection back to our ideas after a couple of decades.

MF - CJ came out like a hurricane. First, in the United States. In a few years, very interesting experiences were underway in Colombia, Argentina, Bolivia, Brazil, Spain, etc. What caused the cooling of this current of contemporary Journalism? Is there a great reason or several factors over the next few years to the initial momentum?

DM: There's certainly no single reason to which I would attribute the "cooling." I can only attest to what I observed in the U.S., and one broad reason was that not enough U.S. journalists took seriously the need for reform, particularly those in major markets. Journalists at major newspapers and networks typically are not open to the suggestion that they are not doing everything right; after all, they are in the Big Time and do not 
consider that they could possiblylearn anything from the editor of a medium-sized, Midwestern newspaper and a very young Journalism professor.

Other reasons, in no particular order:

1. Public Journalism came along in the Nineties just as Wall Street's negative influence on publicly-held newspapers was stripping them of resources in the name of ever-increasing profits. Doing Public Journalism well is not inexpensive and requires some risk-taking. The Nineties were a time when Wall Street profit demands were already cutting into newspaper content. In one sense, I wish we had thought of Public Journalism in the late 1970s or 1980s. The need for reform was clear to some of us even then, but newspapers were making handsome profits and could see no end to them, so why change?

2. Public Journalism had Journalism done to it. I was appalled and disappointed with my first encounters as a subject of journalistic coverage. Both Jay and I experienced many times being interviewed by reporters who had not read our material, including the first manifesto and my "Public Journalism and Public Life."

One day, together we spent more than five hours with a reporter from a prominent Journalism magazine, patiently explaining what we were about. Her story - which was the first major one to appear nationallygot only half of it right and was framed in a way that made us look like itinerant evangelists preaching some sort of new religion of Journalism.

Time and again, reporters would call and say, "Tell me in one paragraph what Public Journalism is about," which is simply not possible, particularly to someone who has not done any homework before calling. I was never interviewed by a U.S. print or broadcast journalist who had properly prepared for the assignment, and I did dozens of interviews. It was all "grab and go" Journalism, like a bad take-out restaurant. By contrast, the several foreign journalists who interviewed me - including from Sweden, Chile, Argentina, Costa Rica, Japan, New Zealand, Australia - had done their homework. 
In one U.S. instance, the Editor Emeritus of The New York Times called, saying he wanted to write an open piece about Public Journalism. From his first few questions, it was clear he had read nothing but that one magazine piece. I said, "If you want to know my views about it, I just finished a book about it. It was published right across the river from you in New Jersey and I can have one on your desk in the morning." He said, "No thank you," and proceeded to write a piece condemning the idea.

3. In part because of the Pew approach, Public Journalism became identified as a method more than as a philosophy; as a bag of journalistic tricks rather than an attitude and belief about journalism's role in the process of democracy. As Wall Street's profit motivation sucked resources out of newsrooms, the possibilities of demonstrating the usefulness of a change of attitude diminished.

Also, because of the Pew approach to funding major projects and because the early coverage of Public Journalism focused on a couple of major projects we did at The Wichita Eagle, the entire movement became identified as project-oriented when, in fact, the newsiest and most interesting aspect of the movement was the effort to change how journalists perceived of third role and responsibility in a democracy. While major reporting projects are expensive, a change is outlook costs nothing except the effort to understand why change is necessary. That part of Public Journalism quickly became lost.

Frankly, a lot of journalists were not-and still are not-interested in the intellectual and philosophical challenge that the movement presented. Some just ignored it. Others said, "Just tell me how to do it; don't bother me with the reasons." Still others did not understand-or want to understand - that how they did their job had a great deal to do with how public life functioned. They refused to accept responsibility for the way they collected and presented information: we just tell the news.

MF: Many thinkers became CJ experts in the early years. Jay Rosen and Jan Schaffer in the United States, for example. Ana Maria Castellanos in Colombia. Carlos Castilho and Luiz Martins in Brazil. Francisco Seoane in Spain. In Portugal, Nelson 
Traquina. And Sabrina Carrasco in Argentina. Have you been following any writer in recent years about the Civic Journalism?

DM: It has been a very long time since I have read anything about Pubic Journalism anywhere. If it has still been a matter of interest beyond the U.S. in the last ten years or so, I am not aware of it. As far as the U.S, is concerned, it faded away by about 2003.

MF: A controversial issue has always been the nomenclature. Today, you prefer to speak in Public Journalism instead of Civic Journalism. What can be said about the relevance of this issue?

DM: The nomenclature is very relevant insofar as historical accuracy is concerned. When Jay and I were debating what to call it, I wryly suggested "Banana," simply as a way of avoiding the name getting in the way of the objectives. Pew choosing to call it "civic" did indeed cause confusion and, in my view, hurt the cause we all were trying to achieve.

MF: Another item that has always attracted a lot of attention: the Civic Journalism seems to be better suited to Printed Journalism, especially small and medium-sized daily newspapers. With the decadence of this type of media, may be an explanation for the CJ also not have progressed so much?

DM: As I mentioned above, the larger news media simply did not see the need to change, despite a lot of research demonstrating that need. Broadcast Journalism in the U.S. has always been about ratings first, not the impact of its Journalism on public life and Democracy. Also, the ideas of pubic Journalism were naturally appealing to smaller newspapers because the people who run and own those papers are closer to their communities and the people in them; they are much better positioned to understand the importance of their newspapers playing a useful part of the societies they serve. But in truth, Public Journalism - particularly the attitude part of it - is well suited to any form of Journalism, including Digital.

MF - Authors such as the Brazilian Silvia Moretzshon point out that Journalism 'is historically justified by the En- 
lightenment ideal of enlightening citizens. Does not the CJ seem to you that high ideal to a maximum level?

DM: Most certainly. All civilizations which aspire to individual freedom and self-governance require three important components: a body of shared information, a method or place to discuss the implications of that information, and some shared values-at the least a belief in freedom itself. Journalism at its best provides shared information and ways of discussing what to do about that information, and therefor supports the idea of freedom. The purpose of Public Journalism is to do those things unself-conscienciously; that is, purposefully, rather that just as an artifact of the activity of reporting news. To say, as too many U.S. journalists do, that "my job is just telling the news; what people do with it is of no concern to me," is to not only deny human reality but also to reject any responsibility for the consequences of how they do that job.

MF: Robert Merton and Paul Lazarsfeld, American thinkers, wrote that much of society used to go to sleep with a clear conscience - for supposedly well informed but effectively doing nothing to change social reality. Is the Civic Journalism an attempt to end this 'narcotizing dysfunction', as the two thinkers have defined it?

DM: That's a great term, "narcotizing dysfunction." The ultimate goal for Public Journalism wasn't simply to reform the practice of Journalism. But reform was a necessary step to reach the ultimate goal of helping public life to go better-that is, solve problems, achieve peace and prosperity-by showing people the possibility and value of their engagement in it. Too much of our public life-including political life-and too much of Journalism is practiced in ways that actually discourage people from engaging. Too often, the way stories are conceived and framed defines citizens as bystanders or victims, incapable of meaningful action. Public Journalism, among many other things, seeks to frame stories in ways that demonstrate how citizens can usefully engage in public life.

MF: The CJ is a kind of antithesis of the Mirror Theory, still today an important Theory of Journalism in many parts of the World. Or is it possible to take CJ and Mirror Theory side by side in CJ projects? 
DM: I have never been a fan of the mirror theory it its traditional, simplistic sense, which is, as you suggest, the antithesis of Public Journalism. Holding a mirror up to society will reflect back only what is there and what people in that society choose to see. Society isn't going to self-correct solely on the basis of being told-or shown-how bad it is. Merely reflecting society back upon itself is another way that traditional journalists excuse themselves from responsibility for the way they do their jobs.

MF: In the early 2000s, just as CJ began to lose strength, strands like Open Journalism popped up and even Citizen Journalism changed its configuration - many authors celebrated blogs and the possibilities that anyone could post their comments on the Internet as a new form of Journalism. Open Journalism came to be seen as the salvation of Journalism, which did not happen. Today, what do you think of this whole scenario?

DM: The scenario is terrifying for public life, and presents too large a set of questions to be dealt with here. As noted above, shared information is a necessary component of self-governance. "Open Journalism" is a misnomer; an abuse of the term. Journalism is more than collecting and distributing data; real Journalism has a curatorial component and a context-providing component. Journalistic organizations have a structure, a decision-making hierarchy. Merely passing along words and opinions does not qualify as Journalism in any meaningful sense. I think it likely that, over time, some truly journalistic entities will emerge as internet providers of properly-curated, shared and trustworthy information. But until then, the world is in for a rough and confusing ride. I hope democracy survives this adolescent stage.

MF: In the mid-2000s, Professor Lewis Friedland (Wisconsin University / USA) led an impressive investigation that mapped more than 600 projects in his country about CJ. Now, would it be time to think about a new diagnosis, after 30 years, maybe even involving other countries? If so, is it possible to predict a result?

DM: It would be interesting if someone could replicate the high lev- 
el of research that Lew used. I could not predict the result of such a well-formulated research project. Did Public Journalism survive its birth pangs and do vestiges of it still exist in some places today? Have, after all, some journalists' come to understand their roles differently? What differences have those events made in the public life of the communities in which they occurred? Lots of food for thought there, but a very tough project to undertake.

MF: Of all the projects of CJ that you helped to construct or monitored the news, what can be highlighted as special, either by the method employed or by the results obtained?

DM: The changes in election coverage that the Eagle developed in the early 1990s would be high on a list of effective projects, in part because it was done quite deliberately as an experiment, and the results were authenticated by follow-up research. During an election season, two things are going on: the campaign and the election. The campaign is what the politicians and their handlers do. The election-that is, deciding who to vote for-is what the people do. Traditional election coverage had always been focused on the campaign. We decided to focus our coverage on the election-the job the face. We surveyed voters to find out what concerned them about their lives. We then asked the candidates for their position on those citizen concerns as a major part of our coverage, along with the normal coverage of campaign events. After the election, we researched voter turnout and found that it was higher than normal in the geographic areas were our newspaper circulated and lower than normal in other places. We also tested voter salience-how well voters understood the issues-in our area and outside our area. Voters with access to our coverage understood the issues much more deeply than voters who did not see our coverage.

During the next election cycle, other newspapers in other states used our approach and got similar results. This approach did not sit well with candidates and their handlers because it switched as least some of the control over events and issues onto the side of citizens. That, of course, was our objective.

\section{MF: In 2015, Jan Schaffer speaked that of all the projects sup-}


ported by the Pew Center on Civic Journalism, $78 \%$ presented some kind of solution to the problems that were dealt with in these projects and that more than $50 \%$ of the sponsored proposals had solutions presented by the citizens themselves / readers. They are spectacular percentages, right?

DM: That was the objective of Public Journalism from the beginning: to do Journalism in ways that helped citizens engage in solving our society's problems. It worked in those places where journalists understood the concepts and bought into them.

MF: Is there a future for Civic Journalism, especially at this time when we live with the ubiquity of Fake News? It is not too much to remember that in 2005, Allan Wolper (in text for Editor \& Publisher magazine) decreed the death of Civic $J$, at the time of the transformation of the Pew Center for Civic Journalism into J-Lab: The Institute for Interactive Journalism ...

DM: I did not see Wolper's piece. By 2005, Public Journalism was no longer on the agenda of most newspapers because there was neither time nor money for serious experimentation.

MF: And is there a future for daily Print Media? Or, rather, is there a good future for information that is duly checked in Print Media, or is Journalism bound to be absorbed slowly by content that is made just for fun?

DM: As I wrote in "Knightfall" in 2006, the issue for free societies is not whether newspapers survive - they will not because their financial model is destroyed. The issue is whether the kind of Journalism that traditional, legacy newspapers have always done can be migrated onto digital platforms. So far, there is little evidence that is occurring. As I mentioned above, journalistic organizations that understand and perform the traditional curatorial and contextual tasks while gathering and presenting information can function just as successfully in the digital world as in the world of print. But the issue is whether enough people are willing to pay enough money to support 
that effort online, where most people expect everything to be free. We don't know what a successful business model for online Journalism looks like, and we don't have very much time left to find out. That's the discouraging part.

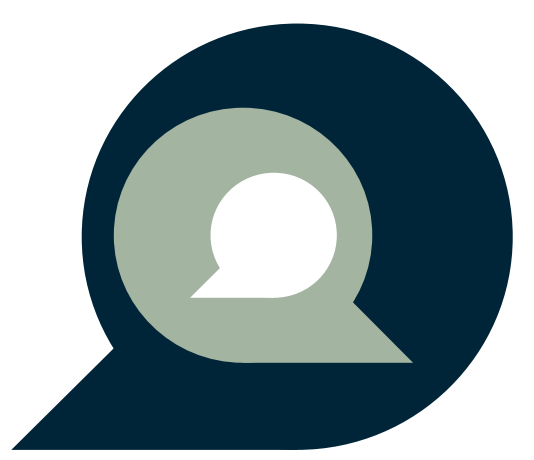

